\title{
Monitoring Aliran Arus Pasang Surut Air Laut Berbasis Arduino
}

\author{
Bambang S. ${ }^{*}$, Rindy C. ${ }^{2}$, Yudhi ${ }^{3}$, Ocsirendi ${ }^{4}$, Sidhiq Andriyanto ${ }^{5}$ \\ 1,2,3,4,5 Politeknik Manufaktur Negeri Bangka Belitung, Indonesia, Jurusan Teknik \\ Elektro dan Informatika
}

e-mail: *1 bambangskuyyyy@gmail.com, ${ }^{5}$ andriyanto.sidhiq@gmail.com

\begin{abstract}
Abstrak
Pasang surut air laut merupakan fenomena alam yang disebabkan oleh perubahan ketinggian air laut di waktu tertentu setiap harinya dan memberikan pengaruh besar dalam melihat karakteristik perairan laut Indonesia. Informasi mengenai pasang surut sangat berguna bagi kegiatan manusia yang berhubungan dengan kelautan seperti menangkap ikan maupun kegiatan lainnya. Maka dari itu diperlukan alat yang dapat memonitoring aliran arus pasang surut air laut. Tujuan pembuatan alat ini adalah untuk membuat alat yang dapat mengukur kecepatan arus dan ketinggian air laut menggunakan basis Arduino. Metode pengukuran kecepatan arus berdasarkan prinsip putaran turbin air dengan pembacaan oleh sensor optocoupler sedangkan pengukuaran ketinggian air laut berdasarkan prinsip konstanta dengan pembacaan sensor ultrasonik. Alat ini dapat merekam hasil pengukuran ke dalam media penyimpanan data SD card dan ditampilkan di LCD. Dari hasil pengujian sensor optocoupler dengan perbandingan alat dan tachometer didapatkan persentase kesalahan 1,17\%. Untuk pengujian sensor ultrasonik dalam pembacaan jarak untuk menentukan ketinggian air laut dengan membandingkan nilai sensor terhadap penggaris didapatkan rata-rata error 1,01\%. Alat monitoring aliran arus pasang surut air laut melakukan pengujian sebanyak 3 kali pengujian dengan hasil pengukuran kecepatan arus sebesar 0,78\% kesalahan alat dan akurasi 99.22\% sedangkan pengukuran ketinggian air laut sebesar 0,38\% kesalahan alat dan akurasi alat $99.62 \%$ yang didapat dari membandingkan alat monitoring dengan alat ukur tachometer dan meteran.
\end{abstract}

Kata Kunci-kecepatan arus, ketinggian air laut, optocoupler, ultrasonik.

\begin{abstract}
The ocean tides is a natural phenomenon caused by changes in sea level at certain times of the day and has a major influence in seeing the characteristics of Indonesian marine waters. Information about tides is very useful for human activities related to the sea such as fishing and other activities. Therefore we need a tool that can monitor the flow of tidal currents in sea water. The purpose of making this tool is to make a tool that can measure the speed of currents and the level of sea water using the Arduino base. The method of measuring current velocity is based on the working principle of the turbine fan and the optocoupler sensor, while the measurement of sea level is based on ultrasonic sensors. This tool can record the measurement results onto the $S D$ card data storage media and displayed on the LCD. From the test results of the FC-03 optocoupler sensor by comparing the tool and the tachometer, the error percentage is $1.17 \%$. For testing the ultrasonic sensor in reading the distance to determine the level of sea water by comparing the sensor value against the ruler, an average error of $1.01 \%$ is obtained. The tidal flow monitoring tool carried out the test 3 times with the results of measuring the flow velocity of $0.78 \%$ tool error and $99.22 \%$ accuracy, while sea water level measurement was $0.38 \%$ tool error and $99.62 \%$ tool accuracy obtained from comparing monitoring tools with measuring instruments tachometer and meter.
\end{abstract}

Keywords-current velocity, sea level, optocoupler, ultrasonic. 


\section{PENDAHULUAN}

Pasang surut adalah salah satu fenomena alam yang terlihat dari pergerakan naik dan turunnya permukaan air laut secara berkala akibat dari kombinasi gaya gravitasi dan gaya tarik menarik benda-benda astronomi seperti matahari, bumi dan bulan yang paling utama. Sedangkan pengaruh dari benda angkasa lainnya dapat diabaikan dalam fenomena pasang surut air laut dikarenakan jaraknya yang sangat jauh atau ukurannya sangat kecil [1], [2].

Dalam kehidupan manusia di bidang kelautan, pasang surut yang terjadi setiap hari sangat penting untuk dikaji untuk keperluan seperti bidang pembangunan pelabuhan, geologi, lingkungan, bidang biologi dan pertanian, serta pengembangan pembangkit listrik tenaga pasang surut [3]-[5].

Kemajuan teknologi informasi dan komunikasi (TIK) yang cepat membuat kemudahan bagi manusia untuk melakukan komunikasi dan mendapatkan informasi yang tidak terbatas oleh waktu. Salah satu contoh pemanfaatan TIK adalah bidang kelautan khususnya tentang pasang surut [6], [7]. Setiap hari, fenomena pasang surut terjadi dan informasi mengenai fenomena tersebut sangat berguna bagi kegiatan manusia yang berhubungan dengan kelautan seperti menangkap ikan maupun kegiatan lainnya [3], [8].

Hidro Oceanografi merupakan suatu kegiatan yang secara khusus mempelajari tentang sifat-sifat dari pergerakan air laut yang meliputi pasang surut, gelombang laut dan arus laut [9]. Kegiatan ini sangat penting dilakukan sebagai pendukung untuk keselamatan bernavigasi para nelayan yang akan keluar masuk pelabuhan, selat atau muara. Kegiatan ini juga dilakukan untuk mengetahui karakter pasang surut air laut [10]-[12].

Metode pengukuran ketinggian air laut dilakukan menggunakan metode mistar meteran dan hanya mampu mengambil data per jam. Sedangkan kecepatan aliran arus diukur menggunakan alat valeport 106. Manusia memiliki keterbatasan dalam kecepatan dan akurasi dalam pengukuran pada setiap saat waktu yang telah ditentukan[13]-[15].

Untuk mendapatkan informasi mengenai pasang surut air laut yang bisa didapatkan dengan mudah dan praktis bagi semua orang, maka dilakukan pembuatan alat yang dapat memonitoring ketinggian air laut dan kecepatan aliran arus pasang surut air laut yang dapat diakses datanya menggunakan penyimpanan offline [16]-[18]. Oleh karena itu pada Proyek Akhir ini akan dirancang, dibuat dan dilakukan uji coba alat monitoring pasang surut air laut dengan penyimpanan offline yang nantinya dapat digunakan pada kawasan perairan laut [19]. 


\section{METODE PENELITIAN}

Diagram alir pelaksana ditunjukkan pada Gambar 1.

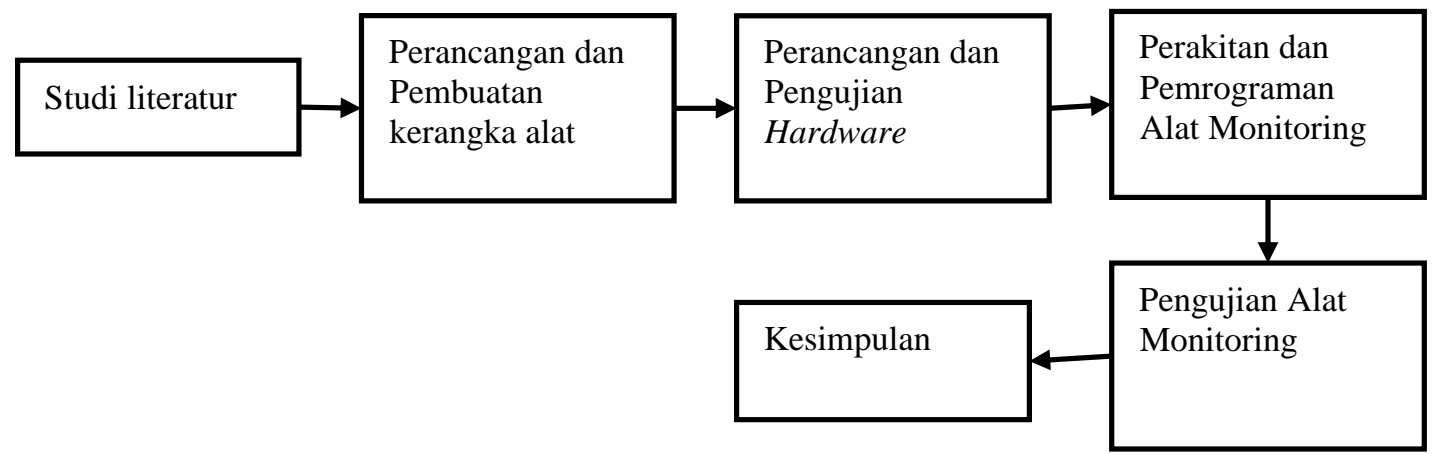

\section{Gambar 1 Diagram Alir pelaksanaan}

1. Studi Literatur

Studi literatur dilakukan dengan cara mencari referensi-referensi dari jurnal artikel dan website yang masih berkaitan dengan alat monitoring aliran arus pasang surut air laut berbasis arduino.

2. Perancangan dan Pembuatan Kerangka Alat

Kerangka alat digunakan untuk meletakkan kontrol dan sensor agar dapat bekerja secara optimal, kerangka alat ini meliputi tiang utama dan turbin air.

\section{Perancangan dan Pengujian Hardware}

Perancangan dan pengujian hardware dilakukan untuk mengetahui apakah komponen yang digunakan berfungsi dengan baik atau tidak. Pengujian yang dilakukan yaitu pengujian sensor optocoupler dan sensor ultrasonik.

4. Perakitan dan Pemrograman Alat Monitoring

Perakitan alat monitoring yaitu dengan merakit box kontrol dengan kerangka alat. Pemrograman sensor optocoupler yaitu menggunakan prinsip putaran dari disc encoder 20 hole sedangkan pemrograman sensor ultrasonik menggunakan prinsip konstanta yaitu dengan menentukan tinggi awal dari dasar laut sampai ke sensor yang dapat dilihat pada gambar di bawah ini [20], [21].

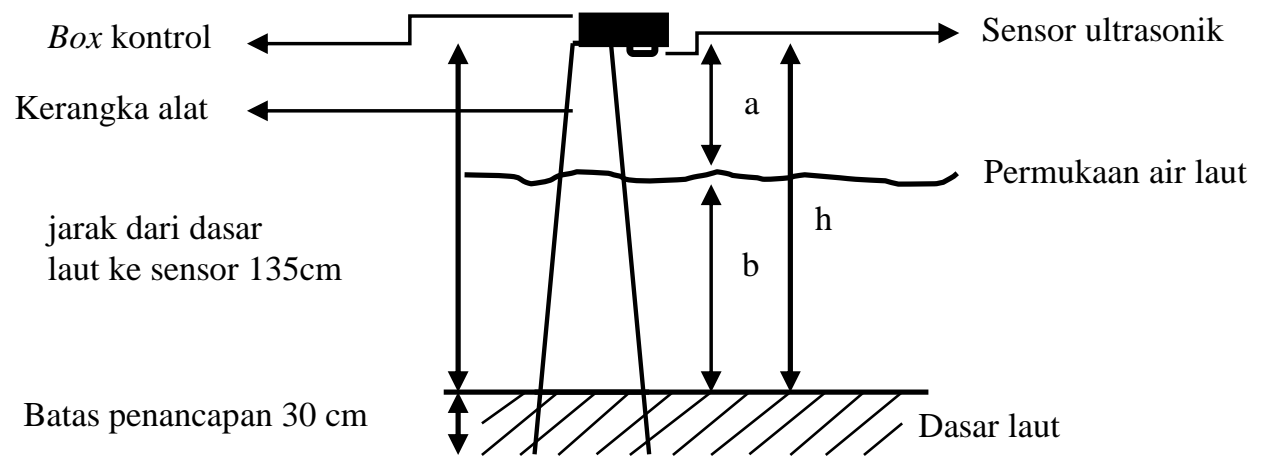

Gambar 2 Konstanta ketinggian air laut 
Jurnal ELECTRA : Electrical Engineering Articles

Vol.2, No.1, September 2021, pp. 1 8

ISSN: 2747-0539 (Online) /2745-598X (Print)

5. Pengujian Alat Monitoring

Pengujian alat monitoring dilakukan di lokasi pantai yang terletak di belakang kampus Politeknik Manufaktur Bangka Belitung di wilayah pantai desa Nelayan 2.

\section{HASIL DAN PEMBAHASAN}

\subsection{Hasil Rancangan Kerangka Alat}

Hasil rancangan kerangka alat ditunjukkan pada Gambar 3. Kerangka alat yang telah jadi ditunjukkan pada Gambar 4.

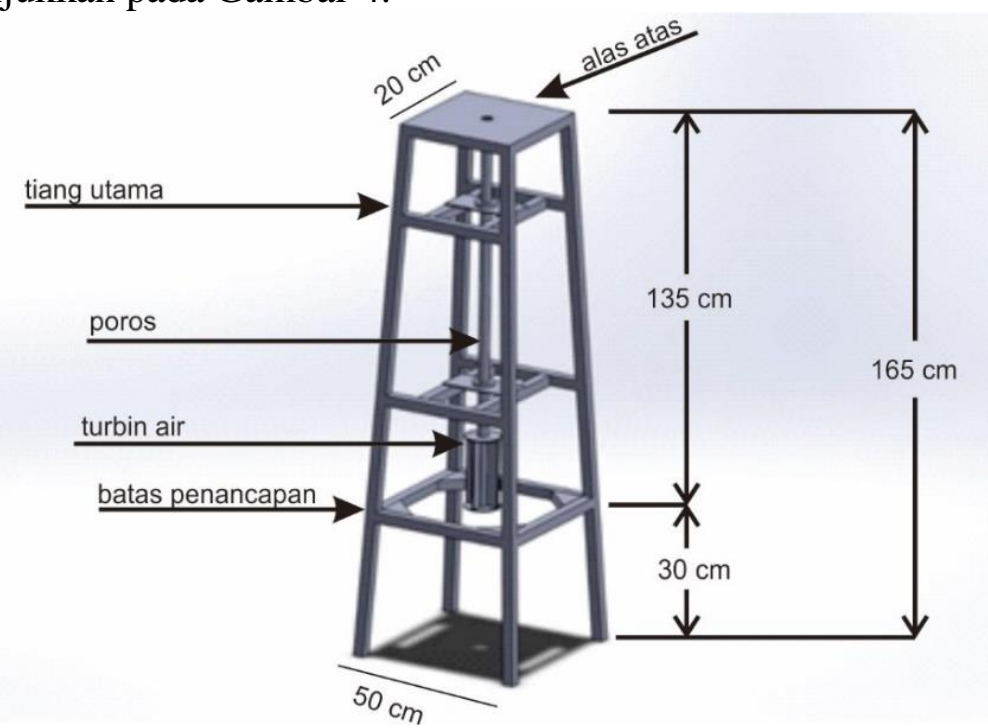

Gambar 3 Rancangan Kerangka Alat

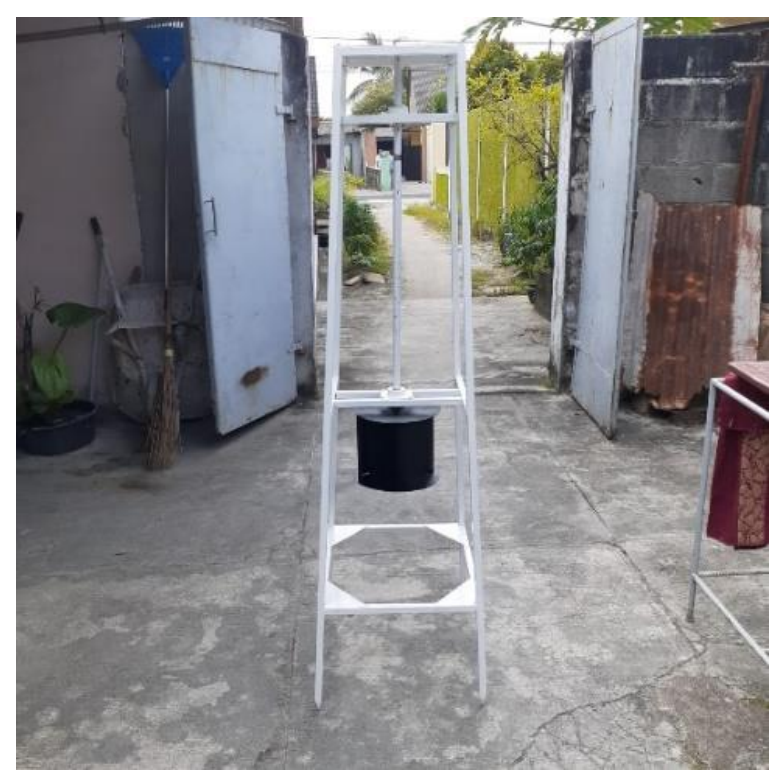

Gambar 4 Kerangka Alat yang telah jadi 


\subsection{Hasil Pengujian Hardware}

3.2.1. Hasil Pengujian Sensor Optocoupler FC-03

Pengujian sensor optocoupler dilakukan dengan cara membandingkan hasil pembacaan sensor dengan alat ukur tachometer. Hasil pengujian sensor optocoupler dapat dilihat pada Tabel 1 di bawah ini.

Tabel 1 Hasil Pengujian Sensor Optocoupler FC-03

\begin{tabular}{cccc}
\hline No. & Sensor optocoupler $(\mathrm{rpm})$ & Tachometer $(\mathrm{rpm})$ & Kesalahan sensor \\
\hline 1. & 99 & 99,5 & $0,50 \%$ \\
2. & 117 & 113,7 & $2,90 \%$ \\
3. & 123 & 123,8 & $0,65 \%$ \\
4. & 145 & 144,0 & $0,69 \%$ \\
5 & 142 & 143,6 & $1,11 \%$ \\
\multicolumn{2}{l}{ Rata-rata persentase error } & $1,17 \%$ \\
\hline
\end{tabular}

\subsubsection{Hasil Pengujian Sensor Ultrasonik HY-SRF05}

Pengujian sensor ultrasonik dilakukan dengan cara membandingkan hasil pembacaan sensor dengan penggaris $30 \mathrm{~cm}$. Hasil pengujian sensor ultrasonik dapat dilihat pada Tabel 2 di bawah ini.

Tabel 2 Hasil Pengujian Sensor Ultrasonik HY-SRF05

\begin{tabular}{cccc}
\hline No. & Penggaris $(\mathrm{cm})$ & Sensor ultrasonik $(\mathrm{cm})$ & Kesalahan sensor \\
\hline 1. & 10 & 10,09 & $0,90 \%$ \\
2. & 15 & 14,52 & $3,20 \%$ \\
3. & 20 & 20,05 & $0,25 \%$ \\
4. & 25 & 25,10 & $0,40 \%$ \\
5 & 30 & 30,09 & $0,30 \%$ \\
\multicolumn{2}{c}{ Rata-rata persentase error } & $1,01 \%$ \\
\hline
\end{tabular}

\subsubsection{Perakitan dan Pemrograman Alat Monitoring}

Setelah box kontrol dan kontruksi alat terhubung, selanjutnya membuat program keseluruhan untuk Arduino Nano menggunakan software Arduino IDE. Pemrograman yang dibuat antara lain:

1. Program sensor FC-03 mendeteksi kecepatan arus pasang surut air laut

2. Program sensor HY-SRF05 mendeteksi ketinggian air laut

3. Program menampilkan data ke layar LCD

4. Program menyimpan data ke SD card

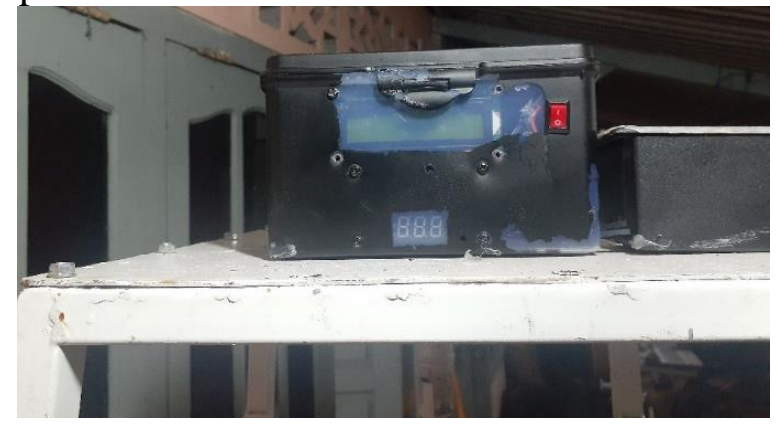

Gambar 5 Perakitan box kontrol dengan kerangka alat 
Jurnal ELECTRA : Electrical Engineering Articles

Vol.2, No.1, September 2021, pp. 1 8

ISSN: 2747-0539 (Online) /2745-598X (Print)

3.2.4. Hasil Pengujian Alat

Pengujian alat dilakukan sebanyak 3 kali yaitu pada tanggal 2, 10 dan 11 Maret 2021. Pengujian dilakukan selama 3-4 jam. Hasil pengujian alat adalah sebagai berikut.

Tabel 3 Hasil Pengujian Tanggal 2 Maret 2021

\begin{tabular}{ccccccc}
\hline Waktu & \multicolumn{3}{c}{ Kecepatan Arus Laut } & \multicolumn{3}{c}{ Ketinggian Air Laut } \\
& $\begin{array}{c}\text { Alachometer } \\
\text { (rpm) }\end{array}$ & $\begin{array}{c}\text { Teteran } \\
(\mathrm{rpm})\end{array}$ & error & Alat $(\mathrm{cm})$ & $\begin{array}{c}\text { Merror } \\
(\mathrm{cm})\end{array}$ & error \\
\hline 13:00:00 & 63 & 62,7 & $0,48 \%$ & 85 & 85,2 & $0,23 \%$ \\
$13: 30: 00$ & 70 & 71,1 & $1,55 \%$ & 79 & 79,4 & $0,50 \%$ \\
$14: 00: 00$ & 79 & 78,8 & $0,25 \%$ & 78 & 78 & $0,00 \%$ \\
$14: 30: 00$ & 85 & 85,1 & $0,12 \%$ & 71 & 72 & $1,39 \%$ \\
$15: 00: 00$ & 91 & 90,5 & $0,55 \%$ & 66 & 67 & $1,49 \%$ \\
$15: 30: 00$ & 100 & 101,1 & $1,09 \%$ & 54 & 54,3 & $0,55 \%$ \\
$16: 00: 00$ & 103 & 103,0 & $0,00 \%$ & 51 & 51 & $0,00 \%$ \\
$16: 30: 00$ & 122 & 123,6 & $1,29 \%$ & 46 & 46,1 & $0,22 \%$ \\
$17: 00: 00$ & 130 & 128,7 & $1,01 \%$ & 42 & 42 & $0,00 \%$ \\
& Rata-rata error & $0,70 \%$ & Rata-rata error & $0,48 \%$ \\
\hline
\end{tabular}

Tabel 4 Hasil Pengujian Tanggal 10 Maret 2021

\begin{tabular}{|c|c|c|c|c|c|c|}
\hline \multirow[b]{2}{*}{ Waktu } & \multicolumn{3}{|c|}{ Kecepatan Arus Laut } & \multicolumn{3}{|c|}{ Ketinggian Air Laut } \\
\hline & $\begin{array}{l}\text { Alat } \\
\text { (rpm) }\end{array}$ & $\begin{array}{c}\text { Tachometer } \\
\text { (rpm) }\end{array}$ & error & Alat $(\mathrm{cm})$ & $\begin{array}{l}\text { Meteran } \\
(\mathrm{cm})\end{array}$ & error \\
\hline 14:00:00 & 89 & 89,3 & $0,34 \%$ & 68 & 68 & $0,00 \%$ \\
\hline 14:30:00 & 92 & 92,4 & $0,43 \%$ & 66 & 66 & $0,00 \%$ \\
\hline $15: 00: 00$ & 94 & 93 & $1,08 \%$ & 65 & 65,4 & $0,61 \%$ \\
\hline $15: 30: 00$ & 98 & 99,3 & $1,31 \%$ & 62 & 61 & $1,64 \%$ \\
\hline $16: 00: 00$ & 104 & 102 & $1,96 \%$ & 59 & 60 & $1,67 \%$ \\
\hline $16: 30: 00$ & 118 & 119,1 & $0,92 \%$ & 59 & 59,2 & $0,34 \%$ \\
\hline \multirow[t]{2}{*}{ 17:00:00 } & 135 & 134,2 & $0,60 \%$ & 59 & 59 & $0,00 \%$ \\
\hline & \multicolumn{2}{|c|}{ Rata-rata error } & $0,94 \%$ & \multicolumn{2}{|c|}{ Rata-rata error } & $0,60 \%$ \\
\hline
\end{tabular}

Tabel 5 Hasil Pengujian Tanggal 11 Maret 2021

\begin{tabular}{|c|c|c|c|c|c|c|}
\hline \multirow[b]{2}{*}{ Waktu } & \multicolumn{3}{|c|}{ Kecepatan Arus Laut } & \multicolumn{3}{|c|}{ Ketinggian Air Laut } \\
\hline & $\begin{array}{l}\text { Alat } \\
\text { (rpm) }\end{array}$ & $\begin{array}{c}\text { Tachometer } \\
\text { (rpm) }\end{array}$ & error & Alat $(\mathrm{cm})$ & $\begin{array}{c}\text { Meteran } \\
(\mathrm{cm})\end{array}$ & error \\
\hline 13:00:00 & 72 & 73 & $1,37 \%$ & 76 & 76 & $0,00 \%$ \\
\hline $13: 30: 00$ & 75 & 74,8 & $0,27 \%$ & 73 & 73,2 & $0,27 \%$ \\
\hline 14:00:00 & 79 & 78,2 & $1,02 \%$ & 70 & 70 & $0,00 \%$ \\
\hline 14:30:00 & 85 & 85,3 & $0,35 \%$ & 67 & 67,2 & $0,30 \%$ \\
\hline 15:00:00 & 93 & 93,4 & $0,43 \%$ & 64 & 64 & $0,00 \%$ \\
\hline $15: 30: 00$ & 104 & 102,9 & $1,07 \%$ & 61 & 61 & $0,00 \%$ \\
\hline \multirow{2}{*}{ 16:00:00 } & 116 & 115,4 & $0,52 \%$ & 58 & 58 & $0,00 \%$ \\
\hline & \multicolumn{2}{|c|}{ Rata-rata error } & $0,71 \%$ & \multicolumn{2}{|c|}{ Rata-rata error } & $0,08 \%$ \\
\hline
\end{tabular}




\section{KESIMPULAN}

Berdasarkan pembuatan Proyek Akhir yang telah dilakukan, maka diambil kesimpulan sebagai berikut :

1. Pengujian sensor optocoupler FC-03 dilakukan dengan membandingkan nilai pembacaan sensor dengan alat ukur tachometer dan didapatkan rata-rata persentase error $1,17 \%$.

2. Pengujian sensor ultrasonik HY-SRF05 dilakukan dengan membandingkan hasil pembacaan sensor dengan penggaris $30 \mathrm{~cm}$ dan didapatkan rata-rata persentase error $1,01 \%$

3. Alat monitoring aliran arus pasang surut air laut melakukan pengujian sebanyak 3 kali pengujian dengan hasil pengukuran kecepatan arus sebesar 0,78\% kesalahan alat dan akurasi $99.22 \%$ sedangkan pengukuran ketinggian air laut sebesar 0,38\% kesalahan alat dan akurasi alat $99.62 \%$ yang didapat dari membandingkan alat monitoring dengan alat ukur tachometer dan meteran.

\section{DAFTAR PUSTAKA}

[1] Fadilah, Suripin, and D. P. Sasongko, "Menentukan Tipe Pasang Surut dan Muka Air Rencana Perairan Laut Kabupaten Bengkulu Tengah Menggunakan Metode Admiralty," Maspari J., vol. 6, no. 1, pp. 1-12, 2014.

[2] I. M. Agus Mahardiananta, R. S. Hartati, and A. Dharma, "Analisa Potensi Energi Pasang Surut Air Laut di Selat Pulau Serangan," J. SPEKTRUM, vol. 4, no. 1, p. 15, 2017, doi: 10.24843/spektrum.2017.v04.i01.p03.

[3] M. M. Khoir, "RANCANG BANGUN ALAT MONITORING PASANG SURUT AIR LAUT BERBASIS INTERNET OF THING (IoT)," UNIVERSITAS ISLAM NEGERI SUNAN AMPEL SURABAYA, 2018.

[4] S. Barus, A. Tanjung, and M. Ghalib, "Pola Arus Pasang Surut dan Gelombang di Perairan Teluk Bayur Kota Padang Provinsi Sumatera Barat Oleh Sastrawan Barus 1), Afrizal Tanjung 2) dan Musrifin Ghalib 2)," J. Online Mhs., 2016.

[5] M. N. Adibhusana, I. G. Hendrawan, and I. W. G. A. Karang, "Model Hidrodinamika Pasang Surut di Perairan Pesisir Barat Kabupaten Badung, Bali," J. Mar. Aquat. Sci., vol. 2, no. 2, p. 54, 2016, doi: 10.24843/jmas.2016.v2.i02.54-59.

[6] S. Irawan, R. Fahmi, and A. Roziqin, "Kondisi Hidro-Oseanografi (Pasang Surut, Arus Laut, Dan Gelombang) Perairan Nongsa Batam," J. Kelaut. Indones. J. Mar. Sci. Technol., vol. 11, no. 1, p. 56, 2018, doi: 10.21107/jk.v11i1.4496.

[7] C. M. Simatupang, H. Surbakti, and A. Agussalim, "Analisis data arus di Perairan Muara Sungai Banyuasin Provinsi Sumatera Selatan," Maspari J., vol. 8, no. 1, pp. 15-24, 2016.

[8] L. Sembel and J. Manan, "Kajian Kualitas Perairan Pada Kondisi Pasang Surut di Teluk Sawaibu Manokwari," J. Sumberd. Akuatik Indopasifik, vol. 2, no. 1, pp. 114, 2018.

[9] M. Lolong, "Hidro Oceanografi Pantai ( Study Kasus Pantai Inobonto )," J. Ilm. Media Eng., vol. 1, no. 2, pp. 127-134, 2011.

[10]T. Al Tanto et al., "Karakteristik Arus Laut Perairan Teluk Benoa - Bali," J. Ilm. Geomatika, vol. 23, no. 1, p. 37, 2017, doi: 10.24895/jig.2017.23-1.631.

[11]A. Pamungkas, "Karakteristik Parameter Oseanografi ( Pasang-Surut , Arus , dan 
Gelombang ) di Perairan Utara dan Selatan Pulau Bangka Abstract Characteristics of Oceanographic Parameters ( Tidal, Flow , and Waves ) in North and South of Bangka Island Bangka Belitung se," Bul. Oseanografi Mar., vol. 7, no. 1, pp. 5158, 2018.

[12]H. Surbakti, "Karakteristik Pasang Surut dan Pola Arus di Muara Sungai Musi, Sumatera Selatan," J. Penelit. Sains, vol. 15, no. 1, pp. 35-39, 2012.

[13]A. Yuningsih and A. Masduki, "Potential Energy of Ocean Current for Electric Power Generationin Coastal Areas of East Flores, Ntt," J. Ilmu dan Teknol. Kelaut. Trop., vol. 3, no. 1, pp. 13-25, 2011, doi: 10.28930/jitkt.v3i1.7831.

[14] Indriani, N. Kurniawati, and M. Hendri, "Simulasi Pemodelan Arus Pasang Surut di Luar Kolam Pelabuhan Tanjung Priok Menggunakan Perangkat Lunak," Maspari J., vol. 01, pp. 79-83, 2010, [Online]. Available: http://download.portalgaruda.org/article.php? article=159487\&val=5974\&title=Sim ulasi Pemodelan Arus Pasang Surut di Luar Kolam Pelabuhan Tanjung Priok Menggunakan Perangkat Lunak SMS 8.1.

[15]P. T. D. Rompas, Heindrich Taunaumang, and Ferry Jhony Sangari, "Sebuah Model Numerik Arus Laut di Selat Bangka Sulawesi Utara dan Analisis Potensi Energi Kinetik untuk Pembangkit Listrik Tenaga Arus Laut," 2016, no. Snttm Xv, pp. 5-6.

[16]. Azhari, M. I. Jumarang, and A. Muid, "Pembuatan Prototipe Alat Ukur Ketinggian Air Laut Menggunakan Sensor Inframerah Berbasis Mikrokontroler Atmega328," Positron, vol. 4, no. 2, pp. 64-70, 2014, doi: 10.26418/positron.v4i2.8729.

[17]D. J. Winarno, "ASANG SURUT DAN ARUS PASANG KAJIAN HIDROOSEANOGRAFI INFRASTRUKTUR PELABUHAN DI SURUT DALAM PENGEMBANGAN TELUK LAMPUNG," 2021.

[18]F. Sari, A. Hendri, and I. Suprayogi, "Aplikasi Model Adaptive Neuro Fuzzy Inference System Untuk Peramalan Pasang Surut di Air Laut ( Study Kasus Pelabuhan Tanjung Buton Siak )," Jom FTEKNIK, pp. 1-6, 2015.

[19]I. M. Radjawane, B. S. C. Saputro, and A. Egon, "Model Hidrodinamika Pasang Surut di Perairan Kepulauan Bangka Belitung," J. Tek. Sipil, vol. 25, no. 2, p. 121, 2018, doi: 10.5614/jts.2018.25.2.5.

[20]A. Putra, "Sistem Monitoring Pengukuran Pasang Surut Air Laut Berbasis Sms Menggunakan Sensor Ultrasonik Dan Komputer Mini," Sustain. Umr., 2015.

[21]N. L. G. R. A. Saraswati, I. W. Arthana, and I. G. Hendrawan, "Analisis Kualitas Perairan Pada Wilayah Perairan Pulau Serangan Bagian Utara Berdasarkan Baku Mutu Air Laut," J. Mar. Aquat. Sci., vol. 3, no. 2, p. 163, 2017, doi: 10.24843/jmas.2017.v3.i02.163-170. 